\title{
Corrigendum
}

\section{VLCD plus dietary and behavioural support versus support alone in the treatment of severe obesity. A randomised two-year clinical trial}

JS:son Torgerson, L Lissner, AK Lindroos, H Kruijer and L Sjöström, Int J Obes 1997; 21: 987-994

In our paper on VLCD treatment of obese men and women, statistical evaluations based on the $\mathrm{chi}^{2}$-method have unfortunately been performed in an incorrect way. This mainly relates to Figure 4 in which the bars as such are correct but, contrary to what is stated in the legend, the bars are not significantly different. In Table $1 \mathrm{~b}$ the chi $^{2}$-test for persons per household is non-significant and $\mathrm{chi}^{2}$-analyses in text without reference to tables and figures are insignificant.

Main results as reflected by remaining figures, tables, abstract and conclusion are not influenced by the $\mathrm{chi}^{2}$-tests. Thus the main conclusion is still true that in obese males an initial 12-week strict VLCDtreatment followed by conventional dietary guidance results in significantly $(P=0.05)$ larger weight reduction at two years $(-15.5 \pm 17.2 \mathrm{~kg})$ than conventional dietary counselling over the whole two-year period $(-5.3 \pm 9.8 \mathrm{~kg})$. This positive effect of VLCD was not observed in women.

We indeed regret having introduced difficulties for the readers in properly interpreting our results.

Göteborg, 5 December 1997 JS:son Torgerson, L Lissner, AK Lindroos, H Kruijer and L Sjöström 